\title{
An Empirical Approach to Estimation of Critical Energies by Using a Quadrupole Ion Trap
}

\author{
Armando Colorado and Jennifer Brodbelt \\ Department of Chemistry and Biochemistry, University of Texas, Austin, Texas, USA
}

A simple energy-resolved mass spectrometric technique is described for the estimation of critical energies for dissociation of ions via threshold collisional activation measurements in a quadrupole ion trap. The method is calibrated by using compounds with well-defined dissociation energies, and separate calibration curves must be constructed for radical ions that are bound by covalent bonds versus hydrogen-bonded complexes. For these sets of experiments, the threshold point is defined as the activation voltage required for the fragment ion intensity to be $10 \%$ of the total ion intensity. A plot of threshold activation voltage of the calibrant versus literature critical energies shows a near-linear function, and accuracies are estimated as better than $\pm 6 \mathrm{kcal} / \mathrm{mol}$. The $q_{z}$ value during activation seems to have little effect on the threshold voltages as long as very low $q_{z}$ values that cause ion ejection are avoided. Activation periods that are substantially longer than 10-ms result in nonlinear behavior in the calibration curves for ions that have critical energies above 30 $\mathrm{kcal} / \mathrm{mol}$. This energy-resolved method was also useful for the estimation of critical energies of complexes bound by electrostatic forces, such as hydrogen-bonding interactions. A quantitative evaluation of proton-bound polyether-amine complexes showed that the number of available hydrogen-binding sites, the gas-phase basicities of the polyether and amine components, and the ability of the complex to attain the most favorable near-linear hydrogen bonds correlate with the threshold values. (C) 1996 American Society for Mass Spectrometry (J Am Soc Mass Spectrom 1996, 7, 1116-1125)

$\mathrm{E}$ nergy resolved mass spectrometry (ERMS) techniques have been in existence for over a decade $[1,2]$. Applications include isomer distinction [3] and evaluation of gas-phase acidities [4], as well as the determination of critical energies (CE) for dissociation of small transition metal dimers [5], water clusters [6], many other metal-containing ions [7], ions produced by electrospray ionization [8], and proton-bound dimers [9]. The critical energy of an ion is the minimum energy necessary for dissociation. Collisional activation dissociation (CAD) and photodissociation (PD) are two methods currently employed to obtain CEs of gas-phase ions. In the CAD technique, the disappearance of the molecular ion of interest and appearance of a specific fragment ion is monitored as a function of energy used to excite the precursor ion. The energy required to induce dissociation is then utilized in the evaluation of the critical energy for dissociation, along with an estimation of the initial internal energy distribution of the precursor ions and RiceRampsberger-Kassel-Marcus (RRKM) correction for kinetic shifts based on the dissociation time scale of the instrument. The application of the modeling theory developed by Armentrout and co-workers [5-7, 10] requires single-collision conditions to maintain a well-

Address reprint requests to Dr. Jennifer Brodbelt, Department of Chemistry and Biochemistry, University of Texas, Austin, Texas 78712. defined activation environment. In addition, as the size of the precursor ion increases, the corrections for thermal and kinetic shifts have an increasingly large impact on extraction of reliable critical energies. Historically, the instruments of choice for estimation of critical energies by energy-resolved collisional activation measurements have been ion beam $[5-7,9,10]$ or triple quadrupole instruments $[4,8,11]$ due to their excellent resolving power, in terms of the ability to define the kinetic energy of an ion prior to the activating collision, and capability to operate the collision region under single-collision conditions. For the method to estimate critical energies by photodissociation, dissociation rate constants are measured as a function of wavelength or internal energy deposited in the ion of interest [12-14]. These rate constants along with RRKM modeling allow dissociation energies to be calculated.

The quadrupole ion trap is a highly versatile and sensitive instrument that has been utilized in many areas of mass spectrometry research, which range from analytical applications [15-21] to more fundamental studies [22-26]. Properties such as proton affinities $[2,23]$, gas-phase basicities [24], and equilibrium constants [25] have been evaluated, and kinetic studies [26] have been undertaken also. Paul traps operated with the typical 1 mtorr of helium, however, cannot be used to estimate critical energies in the same way as 
ion beam or triple quadrupole instruments (i.e., the Armentrout method) for several reasons. First, because the quadrupole ion trap functions in a dynamic mode, the ions have an initially nonzero translational energy distribution and thus there is a potentially large spread in kinetic energies as ions are activated. Second, because the ions undergo multiple acceleration and deceleration cycles dependent on the phase of the rf voltage, the initial internal energies of ions also are defined poorly because the ions undergo a sequence of activating and deactivating collisions with helium. During the accelerating phase of the trapping cycle, ions that collide with helium may experience internal heating to a minor degree. In the absence of additional resonance excitation, ions cool to attain an average translational energy of $<0.2 \mathrm{eV}$ in $1 \mathrm{~ms}$ [27-29] and an average internal temperature of $<400-1000 \mathrm{~K}$ $[30,31]$. Third, the use of 1 mtorr of helium results in a multiple collision activation environment. Ions average 20-50 collisions per millisecond. Moreover, the process of collisional activated dissociation is quite different in a quadrupole ion trap relative to the other types of tandem mass spectrometers. The translational activation of ions in an ion trap is done by application of a supplementary ac voltage across the endcaps (typically from 0.1 to $1.0 \mathrm{~V}$ ). Because a radiofrequency voltage is used to accelerate the ions for collisional activation, ions undergo a continuous interchange between acceleration and deceleration during the activation period. In a typical $10-\mathrm{ms}$ activation period, ions experience several hundred collisions with helium on average, some that result in significant activation and some that result in deactivation depending on the phase of the ac voltage. All of these factors contribute to an environment that cannot be modeled easily and used to extract critical energies by the well-respected strategy developed by Armentrout. On the bright side, in many cases the CAD method in an ion trap is less susceptible to kinetic shifts relative to CAD experiments undertaken in beam-type tandem mass spectrometers because the activation interval is long relative to the time scale required for dissociation by pathways that have rate constants from $10^{3}-10^{14} / \mathrm{s}$. In the ion trap, a typical activation and dissociation period is $10 \mathrm{~ms}$, relative to a $10-\mu$ s period that might be encountered in a beam-type instrument. However, ions must undergo activation on a faster time scale than collisional deactivation in the ion trap to observe fragmentation, so there exists a special type of kinetic shift for trapping experiments. Ion deactivation by infrared radiative cooling creates another source of kinetic shifts [32] in ion traps, but often the rate of radiative cooling scales with the size of the ion, so that these kinetic shifts tend to be relatively uniform for similar classes of molecules.

Recently, Hart and McLuckey [33] from the Oak Ridge National Laboratory observed a logarithmic correlation between the threshold resonant excitation amplitudes (TREA) of ions generated by electron impact and their known critical energy values in a quadrupole ion trap by studying the kinetics of ion decomposition. The method developed by Hart and McLuckey established a new way to measure critical energies of ions and offered promise for use of the ion trap to extract critical energies for other types of ions, but they did not extend their method to noncovalently bound systems. The capabilities of the ion trap for measurement of critical energies should be applicable to many other types of ions because only the highest energy tail of the ion energy distribution is sampled during a threshold measurement, regardless of the specific details of the ion activation process.

This paper introduces a simple ERMS technique that allows critical energies to be estimated directly via threshold activation voltage measurements in a quadrupole ion trap. Critical energies are extrapolated from a calibration curve constructed for ions with well-defined dissociation energies. In this article, the threshold point is defined as the point where only a small fraction of the precursor ions have undergone dissociation $[\sim 10 \%]$. Thus, the method only probes a small percentage of the ions, similar to the method used in other types of tandem mass spectrometers. As described herein, the method that uses the ion trap does not provide the same degree of accuracy as the critical energy measurements accessible in conventional tandem mass spectrometers, but it offers great versatility in the types of ions that can be evaluated in an ion trap. The method provides values that are accurate to within $\pm 5 \mathrm{kcal} / \mathrm{mol}$ (in direct comparison to critical energies reported previously) and has an average standard deviation of $\pm 2 \mathrm{kcal} / \mathrm{mol}$. In this report, critical energies for ions generated by electron impact and ion-molecule association reactions, such as those used to create polyether-amine host-guest complexes, are evaluated [34]. A detailed account of instrumental parameters that affect the collisional activation process of ions that involve cleavage of covalent bonds and hydrogen bonds is presented. The method described in this article differs from the one described by Hart and McLuckey because the present method involves construction of a calibration curve of critical energy values based on measurements reported in the literature, and then the critical energies for new ions are extrapolated based on direct threshold measurements. A detailed kinetic analysis as reported by Hart and McLuckey is not done for each ion, and the extraction of critical energies reported herein is based solely on an empirical relationship.

\section{Experimental}

All experiments were performed in a Finnigan ion trap mass spectrometer operated in the mass selective instability mode [35]. Samples were introduced into the chamber via a leak valve or solids probe inlet at pressures between 6.0 and $8.0 \times 10^{-6}$ torr (uncorrected). The base pressure was raised to $1.2 \times 10^{-4}$ torr $\mathrm{He}$ (uncorrected) after sample pressures had stabi- 
lized. A $q_{z}$ value of 0.4 and an activation time of $10 \mathrm{~ms}$ were used for all experiments unless otherwise noted. A cooling time prior to activation was held at $10 \mathrm{~ms}$. The trap temperature was kept at $120^{\circ} \mathrm{C}$. The range of tickle voltages applied across the endcaps was between 10 and $400 \mathrm{mV}_{\mathrm{p}-\mathrm{p}}$. The exact resonant frequency of the applied tickle voltage was optimized at each new activation voltage used to establish the threshold behavior. The threshold activation voltage was defined as that voltage where the fragment ion intensity is $10 \%$ of the total ion intensity. All samples were purchased from Aldrich Chemical Co. (Milwaukee, WI) with the exception of anhydrous ammonia (MG Industries, Valley Forge, PA).

For the proton-bound dimer experiments, the sample pressures of the hosts (polyethers) and guests (amines) were $1-2$ and $3-4 \times 10^{-6}$ torr (uncorrected), respectively. Helium was introduced into the chamber at a pressure of $1.2 \times 10^{-4}$ torr (uncorrected). Ion-molecule reaction times were in the range of $10-150 \mathrm{~ms}$. All values were obtained by utilizing a $q_{z}$ value of 0.2 as opposed to 0.4 due to the more efficient trapping and detection of low mass ions at $q_{z}=0.2$. For these hydrogen-bound complexes, activation at $q_{z}$ values of 0.3 or higher results in unstable trajectories for the low mass protonated amine fragment ions.

\section{Results and Discussion}

\section{Calibration of Threshold Method}

The dissociation behavior of a series of ions with well-characterized critical energies was examined to establish a calibration of energies in the ion trap. The calibration compounds chosen for this study are listed in Table 1 in the order of increasing critical energy of the molecular ions. A typical threshold plot of fragment ion intensity versus activation voltage applied across the endcaps is shown in Figure 1 for the dissociation of $n$-butylbenzene molecular ions via loss of propene. Table 1 summarizes the complete set of threshold activation voltage measurements obtained in the quadrupole ion trap. The threshold activation voltages correlate well with the gas-phase stabilities of the ions. A plot of threshold activation voltage versus literature critical energies shows a near-linear function (Figure 2). The error bars indicate a low standard deviation in the measurements, and the standard deviation is determined to be $\pm 2.0 \mathrm{kcal} / \mathrm{mol}$ for these ions. A special case is the tetraethylsilane ion which spontaneously dissociates under the standard operating conditions and is therefore considered the lower limit for which critical energies can be measured. It is assigned a value of zero. This result likely stems from two reasons. First, the dynamic trapping conditions of the ion trap, in which ions are continuously accelerated and decelerated in the quadrupolar field, cause some of the ions to undergo heating while others are cooled. Thus, some ions gain internal energy and may dissociate without supplementary activation if the critical energy is sufficiently low. Second, the temperature of the helium bath gas also may contribute to heat the ions, which results in some dissociation of the tetraethylsilane ions. Based on the calibration graph shown in Figure 2, critical energies for other ions can be estimated with an accuracy of $\pm 6 \mathrm{kcal} / \mathrm{mol}$.

To evaluate this technique further, two more systems with less well-studied critical energies were examined. The lowest energy fragmentation pathway for the iron pentacarbonyl molecular ion is the loss of one carbonyl functional group. Currently, conflicting critical energy values for the iron pentacarbonyl system exist in the literature. Norwood et al. [36] (Ames Laboratories) performed PEPICO (photo-electron photo ion-coincidence) experiments and found that the loss of the first carbonyl functional group required $17.8 \pm$ $0.9 \mathrm{kcal} / \mathrm{mol}$. Shultz et al. [37] (University of Utah), on the other hand, determined the critical energy to be $26.8 \pm 0.9 \mathrm{kcal} / \mathrm{mol}$ from collision induced dissociation experiments in an ion beam apparatus. The Utah group, however, explained that the discrepancy between the two numbers was due to a high kinetic shift in the PEPICO experiments. Our collisional activation technique produced a value of $28 \mathrm{kcal} / \mathrm{mol}$, which agreed very well with the critical energy value from the Utah group.

The second system examined was the dissociation of the ferrocene ion. The lowest energy pathway of fragmentation for this ion is the loss of a cyclopentadi-

Table 1. List of threshold activation voltages and critical energies of calibration compounds

\begin{tabular}{llcr}
\hline $\begin{array}{l}\text { Calibration } \\
\text { compounds }\end{array}$ & $\begin{array}{l}\text { Lowest energy } \\
\text { fragment }\end{array}$ & $\begin{array}{c}\text { Threshold activation } \\
\text { voltage }(\mathrm{mV})\end{array}$ & $\begin{array}{c}\text { Literature critical } \\
\text { energy (kcal/mol) }\end{array}$ \\
\hline \hline Tetraethylsilane & loss of $\mathrm{C}_{2} \mathrm{H}_{5}$ & 0 & 11.5 (ref 39) \\
Nitromethane & loss of $\mathrm{CH}_{3} \mathrm{O}$ & $49 \pm 2$ & $16.4 \pm 2$ (ref 40) \\
Butylbenzene & loss of $\mathrm{C}_{3} \mathrm{H}_{6}$ & $72 \pm 6$ & $25.41 \pm 2$ (ref 41) \\
Fe $(\mathrm{CO})_{5}$ & loss of $\mathrm{CO}$ & $85 \pm 5$ & $26.8 \pm 1$ (ref 37) \\
Ethylbenzene & loss of $\mathrm{CH}_{3}$ & $99 \pm 7$ & $30 \pm 2$ (ref 42) \\
Toluene & loss of $\mathrm{H}_{\text {f }}$ & $131 \pm 5$ & $39.3 \pm 2$ (ref 43) \\
Styrene & loss of $\mathrm{C}_{2} \mathrm{H}_{2}$ & $206 \pm 12$ & $56.1 \pm 2$ (ref 44) \\
Ferrocene & loss of $\mathrm{C}_{5} \mathrm{H}_{5}$ & $401 \pm 12$ & $85.5 \pm 7$ (ref 38) \\
\hline
\end{tabular}

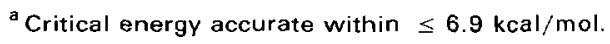




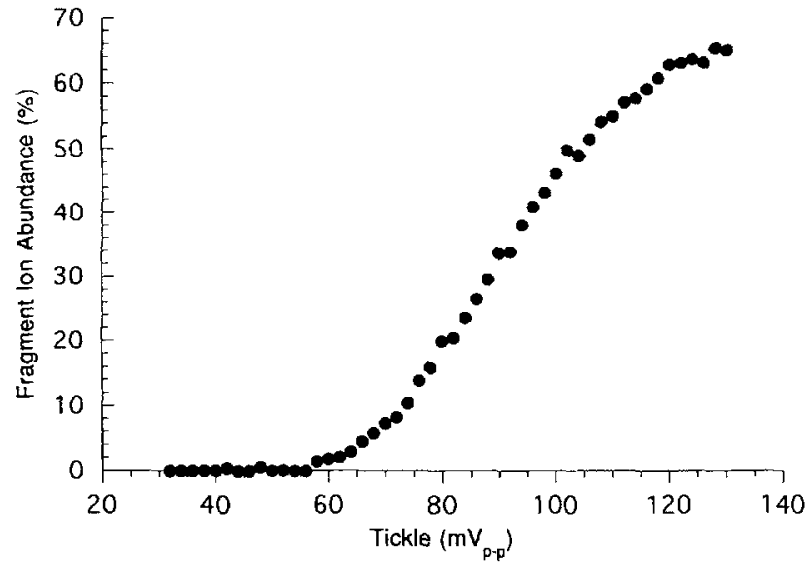

Figure 1. Typical plot of activation voltage versus fragment ion abundance for dissociation of $n$-butylbenzene molecular ions via loss of propene.

enyl functional group. By using time-resolved photodissociation in an ion cyclotron resonance along with RRKM modeling, Faulk and Dunbar determined a

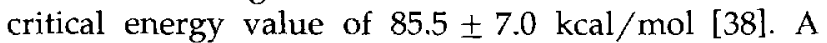
value of $91.9 \mathrm{kcal} / \mathrm{mol}$ also was calculated based on well known thermochemical information [38]. The ion trap technique resulted in a value of $95 \mathrm{kcal} / \mathrm{mol}$, which is close to the values reported in the foregoing text.

\section{Effect of Instrument Parameters on Threshold Activation Voltage}

Activation time and $q_{z}$ value effect. To evaluate the influences of certain instrumental parameters on the measured threshold activation voltage, several systematic studies were undertaken. The main variables of interest included the $q_{z}$ value (a storage condition related to the depth of the potential-well [35]) and the activation time. The $q_{z}$ value appears to have little effect on the measured threshold activation voltages for various ions at $q_{z}$ values between 0.3 and 0.4 , but

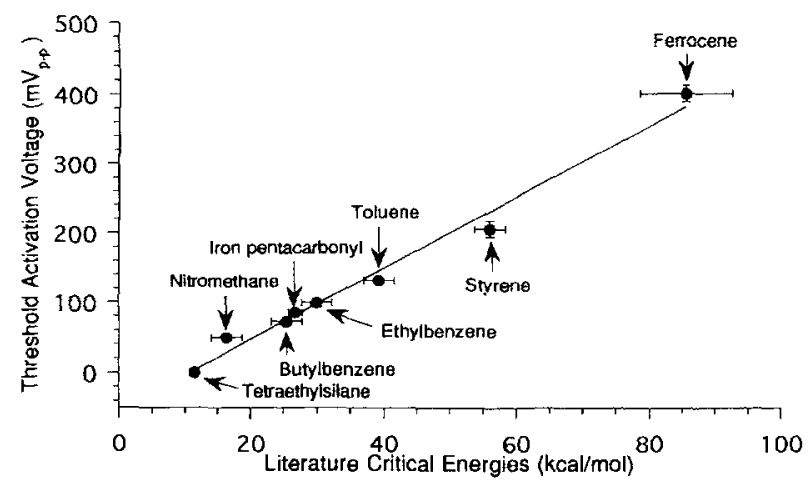

Figure 2. Plot of threshold activation voltage versus literature critical energy. at $q_{z}$ values of $\leq 0.2$, ejection of the precursor ions and inefficient formation of fragment ions is observed. The activation time has a noticeable effect, especially for ion dissociation pathways with large critical energies. Three activation times $(10,50$, and $100 \mathrm{~ms})$ were used to examine the change in threshold activation voltage at three different $q_{z}$ values $(0.3,0.35$, and 0.4 ; Figure $3 \mathrm{a}-\mathrm{c}$ ). At an activation time of $10 \mathrm{~ms}$, a linear relationship is exhibited between threshold activation voltage and critical energies. At 50 and $100 \mathrm{~ms}$, however, a nonlinear relationship is observed. At these longer activation times, other processes begin to compete effectively with ion dissociation. Some ionmolecule charge-transfer reactions (i.e., between any ions and background neutrals) occur that deplete some of the fragment ion and precursor ion populations. In
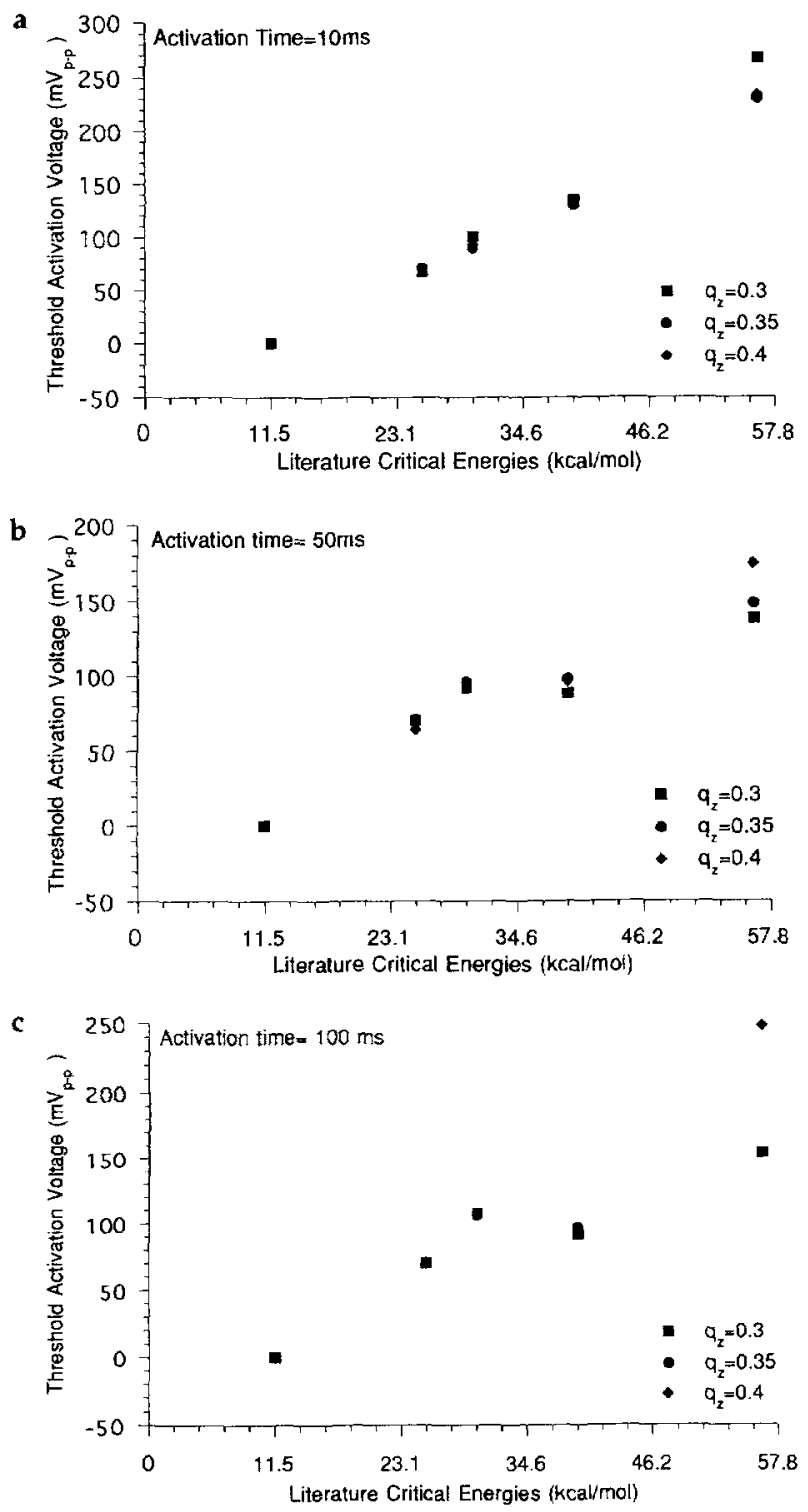

Figure 3. Effect of (a) 10-, (b) 50-, and (c) 100-ms activation times on threshold activation voltage at three different $q$ values. 
addition, a long activation time allows us to sample from a greater portion of the precursor ion population. The precursor ions that are initially slightly hotter are the ones that will dissociate in the first $10 \mathrm{~ms}$. At longer activation times, a wider range of ions with less uniform initial characteristics will dissociate. In addition, longer activation times may change the impact of kinetic shifts because there is a greater amount of time for the slow dissociation of ions that have little excess internal energy. In summary, there are numerous factors that influence the activation process for different activation times and $q_{z}$ values, and a linear correlation between critical energy and threshold activation voltage is not necessarily justified or expected as the conditions are changed. For the objectives of this study, a relatively short activation interval and moderately low $q_{z}$ value yielded the most reproducible and linear behavior for the empirical approach described herein.

Sample pressure effect. Three different sample pressures that range from 2 to $6.8 \times 10^{-6}$ torr of $n$-butylbenzene $(\mathrm{CE}=25.4 \mathrm{kcal} / \mathrm{mol})$ and styrene $(\mathrm{CE}=56.1$ $\mathrm{kcal} / \mathrm{mol}$ ) were used, and the ionization time was adjusted to create the same number of ions for each experiment. Figure 4 shows that sample pressure has no significant effect on the observed threshold activation voltage. The only effect that sample pressure has on the collisional activation process is a decrease in the overall dissociation efficiency. This effect is minor for butylbenzene but highly profound in the activation of styrene. At lower pressures, over $80 \%$ of the styrene ion population undergoes dissociation at voltages between $290-300 \mathrm{mV}_{\mathrm{p}-\mathrm{p}}$. As the sample pressure is increased to 4 and $6 \times 10^{-6}$ torr, only 60 and $40 \%$ of the parent ions dissociate, respectively. This decrease in dissociation efficiency is attributed to an increase in charge-exchange processes between molecular ions, fragment ions, and neutral sample molecules and to a possible increase in ion scattering. These results stress the importance of avoiding overloading the trap with too much analyte pressure to obtain accurate values of critical energies.

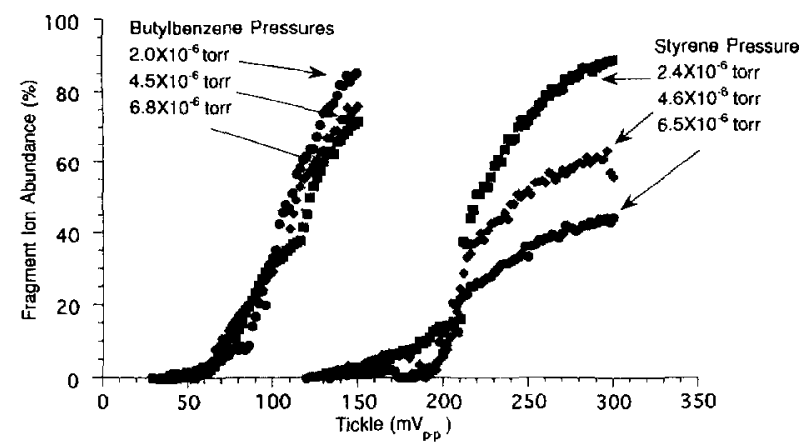

Figure 4. Sample pressure effect of butylbenzene and styrene on threshold activation voltage.

\section{Collisional Activation of Hydrogen-Bonded Complexes}

Because of our long-term interest in understanding the nature of hydrogen-bonding interactions [34], we evaluated the energy-resolved CAD method for complexes bound by electrostatic forces, like for proton-bound dimers. Because proton-bound species are held together by noncovalent bonds, we felt that it was important to check the critical energy calibration curve by using values reported in the literature for proton-bound complexes. Thus, another calibration curve based on the dissociation of proton-bound dimers was constructed [45-48]. Again, a linear correlation was observed for the literature critical energy values and threshold activation voltage measurements (Figure 5). A consistent standard deviation of $\pm 2 \mathrm{kcal} / \mathrm{mol}$ was obtained. The new calibration curve does not match the one constructed for the radical molecular ions, and we offer several reasons for the differences in slopes and intercepts.

First, we have some evidence that the proton-bound complexes initially may have somewhat lower internal energies than those of the radical ions prior to the activation interval. For example, a "cooling" interval, in which the selected precursor ions are stored in the trap for 50-100 ms and undergo several hundred more collisions with helium, may be added prior to collisional activation. For the radical precursor ions, the resulting threshold values shift to higher energies by 3-5 kcal/mol (see Figure 6), but the threshold values do not shift at all for the protonated complexes. This result implies that some of the radical precursor ions initially may be internally hot and thus they cool off during the delay period. The fact that some portion of the ions initially may be hotter than others is not unexpected for the dynamic environment of the ion trap, and for many experimental situations the presence of hot ions would not be noticed. In the threshold measurements, only the $10 \%$ of the ion population with the greatest internal energies are sampled directly, and thus a minor portion of ions that have initially high energies may create a large influence on

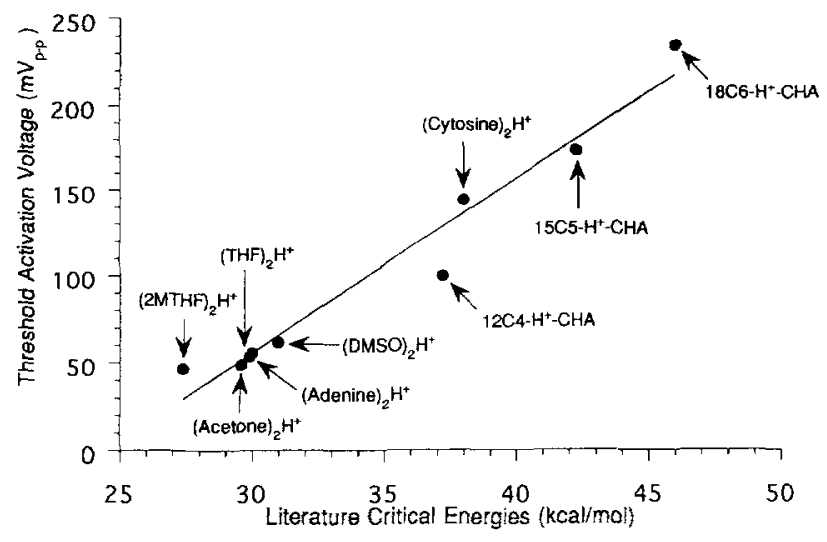

Figure 5. Calibration curve for proton-bound dimers. 


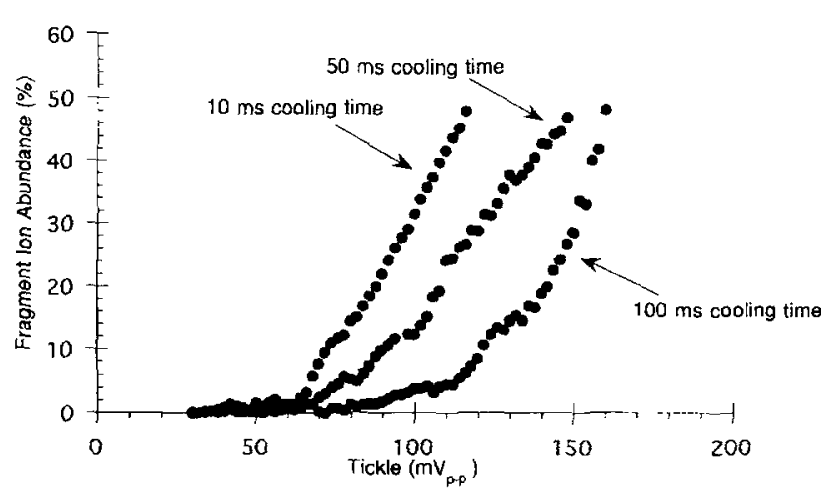

Figure 6. Effect of cooling time on threshold activation voltage of $n$-butylbenzene ions.

the experimental outcome. Because the radical precursor ions are created by electron ionization, it seems reasonable that some portion of those ions might need a longer cooling period prior to activation. The initial internal energy distributions of the various precursor ions will vary relative to the size and structure of the molecule and its available dissociation pathways; thus the internal energy effect is not defined easily in more detail. A similar cooling phenomena is not observed for the proton-bound complexes. The proton-bound complexes are formed by ion-molecule reactions, and thus a $100-\mathrm{ms}$ reaction interval that also allows collisional cooling already is incorporated into the experimental sequence. The ion-molecule reactions also may be less energetic processes than electron ionization. In addition, the proton-bound complexes may cool more efficiently by radiative emission, which thus results in cooler ions prior to activation. In general, it appears that the calibration curve constructed for the radical precursor ions may have a larger deviation due to thermal shifts.

Second, most of the dissociation processes of the radical precursor ions can be classified as direct cleavages of a single covalent bond. In contrast, some of the dissociation processes for the proton-bound species may involve cleavage of several hydrogen-bonding interactions, and thus the kinetics for activation and dissociation of the proton-bound complexes may be quite different than the ones for the radical ions. In addition, the polyether complexes used to construct the upper half of the second calibration curve are substantially larger than the radical ions used to construct the first calibration curve. These two factors suggest that there may be different kinetic and thermal shifts that operate for the systems used for each calibration curve. These thermal and kinetic shifts are difficult to model because of the complexity of the molecular ions, but it is not inconceivable that shifts of $3-7 \mathrm{kcal} / \mathrm{mol}$ could be active for complexes in this size range and on the $10-\mathrm{ms}$ time scale of the activation period. The thermal and kinetic shifts tend to modify the critical energies in opposite directions, so there may be some cancellation in their net contributions.
These shifts undoubtedly contribute some degree of error, and the shifts will become increasingly dominant as larger ions are studied. Therefore, the accuracy of the energy-resolved method described herein also will depend on extention of the calibration curve based on values reported by other groups.

Third, the calibration curve for the proton-bound complexes was acquired by using a $q_{z}$ value of 0.2 for all CAD experiments, whereas the calibration curve for the radical ions described earlier was acquired with a $q_{z}$ value of 0.4 . The use of a low $q_{z}$ value for the proton-bound complexes was necessary to allow low molecular weight ammonium fragment ions to be trapped during investigation of some of the polyether-ammonium ion complexes. At low $q_{z}$ values, such as $q_{z}=0.2$, there is extensive competition between ion ejection and ion dissociation for the radical ions. This phenomena has been characterized extensively previously by Charles et al. [49]. In that earlier study, the competition between ion dissociation and ejection was evaluated for a variety of ions with relatively low molecular weights and different critical energies at a range of conditions. We observed a similar interplay between ion ejection and ion dissociation for the radical ions in this study, so low $q_{z}$ values were avoided for the CAD experiments. For example, the threshold activation voltage of ethylbenzene ions (CE $=30 \mathrm{kcal} / \mathrm{mol}$ ) does not vary between $q_{z}$ values of 0.3 and 0.4 (Table 2), but at $q_{z}$ values of 0.1 and 0.2 , ejection of the ethylbenzene ions is the preferred process and formation of fragment ions is inefficient. In contrast, the proton-bound dimethyl sulfoxide (DMSO) dimer $(\mathrm{CE}=31 \mathrm{kcal} / \mathrm{mol})$ and the $\left[18\right.$-crown- $6+\mathrm{H}^{+}$ $\left.+\mathrm{NH}_{3}\right]$ complex $(\mathrm{CE}=41 \mathrm{kcal} / \mathrm{mol})$ show consistent threshold activation voltages at $q_{z}$ values from 0.2 to 0.4 (Table 2 ). There are several possible rationalizations for the discrepancy in the $q_{z}$-value effect for the radical cations versus the protonated species. First, the radical ions may dissociate by processes that involve greater kinetic energy release, such that the fragment ions may be formed with less stable initial trajectories that result in substantial ejection of the ions. Second, the dissociation of the radical ions involves covalent bond cleavages, whereas the dissociation of the protonated complexes involves cleavage of one or more hydrogen bonds. Differences in the kinetics or dynamics of these cleavages may contribute to the variation in the $q_{z^{-}}$

Table 2. Effect of $q_{z}$ on threshold activation voltage ${ }^{a}$ of radical cations and proton-bound dimers

\begin{tabular}{lccrr}
\hline & \multicolumn{4}{c}{$q_{z}$} \\
\cline { 2 - 5 } Compound & 0.1 & 0.2 & 0.3 & \multicolumn{1}{c}{0.4} \\
\hline \hline Ethylbenzene & $\mathrm{E}^{\mathrm{b}}$ & $\mathrm{E}$ & $95 \mathrm{mV}$ & $99 \mathrm{mV}$ \\
DMSO & $\mathrm{E}$ & $62 \mathrm{mV}$ & $64 \mathrm{mV}$ & $62 \mathrm{mV}$ \\
$18 \mathrm{C} 6-\mathrm{NH4}_{+}$ & $\mathrm{E}$ & $148 \mathrm{mV}$ & $140 \mathrm{mV}$ & $144 \mathrm{mV}$ \\
\hline
\end{tabular}

a Standard deviations of threshold measurements are within $\pm 8 m V$
${ }^{b}$ Ejection is the preferred process. 
value effect. In general, the $q_{z}$-value used for the threshold measurements may contribute to a slight shift in the slope or intercept of calibration curves acquired for the radical ions versus proton-bound complexes.

Because of all the factors outlined in the foregoing text, the construction of a second calibration curve based on proton-bound complexes was necessary. Although the factors responsible for defining slope and intercept of the curve are not well understood, the graph provides one way to empirically calibrate the CAD measurements for different types of ionic systems.

The determination of the intrinsic strength of the hydrogen-bonding interactions is particularly important in molecular recognition, where complexes may be assembled entirely by hydrogen bonds [50-53]. Thus, we wished to develop a quantitative analysis of model host-guest complexes in the gas phase. A series of [polyether $-\mathrm{H}^{+}-$amine] complexes were evaluated to correlate the strength of the hydrogen-bonding interactions with structural features. We have examined the CAD fragmentation patterns of polyetheramine complexes in detail [34], but we were not able to assign absolute association energies. Ion-molecule association reactions were used to generate protonbound complexes, [polyether $-\mathrm{H}^{+}-$amine], between 12-crown-4, 15-crown-5, 18-crown-6, triglyme, or tetraglyme and an amine. Activation experiments showed that the number of available hydrogen-binding sites, the gas-phase basicities of the polyether and amine components (Table 3 ), and the geometry of the interactions correlated with the threshold values (Table 4). For example, the $\left[12-\right.$ crown- $\left.4+\mathrm{H}^{+}+\mathrm{NH}_{3}\right]$ complex dissociated by loss of $\mathrm{NH}_{3}$ at a critical energy value of $32 \mathrm{kcal} / \mathrm{mol}$, whereas the [18-crown- $6+\mathrm{H}^{+}$ $\left.+\mathrm{NH}_{3}\right]$ complex dissociated by loss of $\mathrm{NH}_{3}$ at 41 $\mathrm{kcal} / \mathrm{mol}$. This result suggests that the hydrogen bonds involved in the [18-crown-6 $+\mathrm{H}^{+}+\mathrm{NH}_{3}$ ] complex are optimized because the greater flexibility of the larger polyether ring size allows formation of near-linear hydrogen bonds. Because the 12-crown- 4 molecule is smaller, more rigid, and has only four possible hydrogen-bond acceptors (i.e. the four oxygen atoms), it may form nonlinear, less optimal bonds with ammonia, and protonated 12-crown-4 may adopt a less favorable conformation. Meot-Ner et al. [54] observed similar results in their recent evaluation of polyether-ammonium ion complexes. Part of their study showed that the association energy of protonated 18-crown-6 and $\mathrm{NH}_{3}$ was 40 $\mathrm{kcal} / \mathrm{mol}$, whereas the association energy of protonated 15-crown-5 and $\mathrm{NH}_{3}$ was $36 \mathrm{kcal} / \mathrm{mol}$ [54]. When a tertiary amine is involved in the complexes instead of ammonia, then the critical energies are reduced significantly. For example, the critical energy of the [18-crown-6 $+\mathrm{H}^{+}+\mathrm{N}, \mathrm{N}$-diethylmethylamine] complex is only $34 \mathrm{kcal} / \mathrm{mol}$, and the $\left(12-\right.$ crown $-4+\mathrm{H}^{+}+$ $N, N$-diethylmethylamine] complex is unstable. This result is attributed to the reduction in the number of hydrogens attached to the nitrogen of the guest molecule that can serve as hydrogen-bond donors, therefore fewer bonding interactions are permitted between the amine and crown ether. A similar effect is noted for the comparison of the critical energies for the complexes that involve butylamine versus $\mathrm{N}$-methylbutylamine. The methyl group of $\mathrm{N}$-methylbutylamine reduces the number of potential hydrogen-bonding interactions to the polyether. In Table 4 , the critical energy for the dissociation of the [18-crown- $6+\mathrm{H}^{+}+$ butylamine] complex is listed as $>50 \mathrm{kcal} / \mathrm{mol}$ be-

Table 3. Gas-phase basicities of model guests and hosts

\begin{tabular}{lc}
\hline Compound & $\begin{array}{c}\text { Gas-phase basicity } \\
\text { (kcal/mol) [55] }\end{array}$ \\
\hline \hline 12-Crown-4 & 211.3 \\
15-Crown-5 & 212.5 \\
18-Crown-6 & 216.0 \\
Triethylene glycol dimethyl & 210.8 \\
$\quad$ ether (triglyme) & \\
Tetraethylene glycol dimethyl & 213.2 \\
$\quad$ ether (tetraglyme) & \\
Ammonia & 195.5 \\
$N, N$-diethylmethylamine (N, N-DEMA) & 222.2 \\
Butylamine & 210.6 \\
Ethylenediamine (EDA) & 219.2 \\
1,3-Diaminopropane (1, 3 DAP) & 222.0 \\
Pyridine & 213.1 \\
2-Picoline & 217.2 \\
3-Picoline & 216.2 \\
Cyclohexylamine (CHA) & 213.4 \\
$n$-Propylamine & 210.1 \\
Ethanolamine & 221.3 \\
\hline
\end{tabular}


cause its critical energy exceeded the limits of the calibration curve established in Figure 5 . With the addition of the methyl group to $N$-methylbutylamine, the critical energy for dissociation of the (18-crown-6 $+\mathrm{H}^{+}+\mathrm{N}$-methylbutylamine) complex drops to 41 $\mathrm{kcal} / \mathrm{mol}$.

Complexes between polyethers and diamines also were evaluated. The critical energies for complexes that incorporate ethylenediamine and 1,3 diaminopropane are similar for each of the crown ethers. All of the complexes are more strongly bound ( 34 to $>50$ $\mathrm{kcal} / \mathrm{mol}$ ) than the simpler complexes that involve $\mathrm{NH}_{3}$. This result suggests that each amine functional group can participate in intermolecular hydrogenbonding interactions with the crown ether oxygen atoms, and both ethylenediamine and 1,3-diaminopropane are flexible enough to achieve similar optimized interactions. However, the interaction energy is reduced for $N, N$-dimethylethylenediamine because one nitrogen has two methyl groups instead of hydrogens. This structural change results in a reduction of the binding energy to the crown ethers by up to $10 \mathrm{kcal} / \mathrm{mol}$.
Complexation of a series of pyridines to the polyethers also was examined. The pyridines differ only by the absence or presence of a methyl group, and differences in critical energies for these complexes are minor. The 2-picoline complexes have slightly lower critical energies than the pyridine or 3-picoline complexes. This result could reflect a steric strain on the hydrogen bond formed between the nitrogen atom and the proton and a crown ether oxygen atom with a resulting reduction in the hydrogen-bond enthalpy. These different values, although close in absolute value, are reproducible consistently when the complexes are evaluated sequentially.

Complexes that involve the acyclic glymes (i.e., polyglycol dimethyl ether) also were evaluated; the measured critical energies are summarized in Table 4. The critical energies of the glyme complexes are in most cases comparable to those measured for the analogous crown ether complexes. The greater flexibility of the glymes allows some optimization of the hydrogenbond geometries, but likewise the resulting hydrogenbonds are not as well anchored as they tend to be in the more pre-organized crown ether complexes. These

Table 4. Critical energies of the hydrogen-bonded host-guest complexes studied ${ }^{a}$

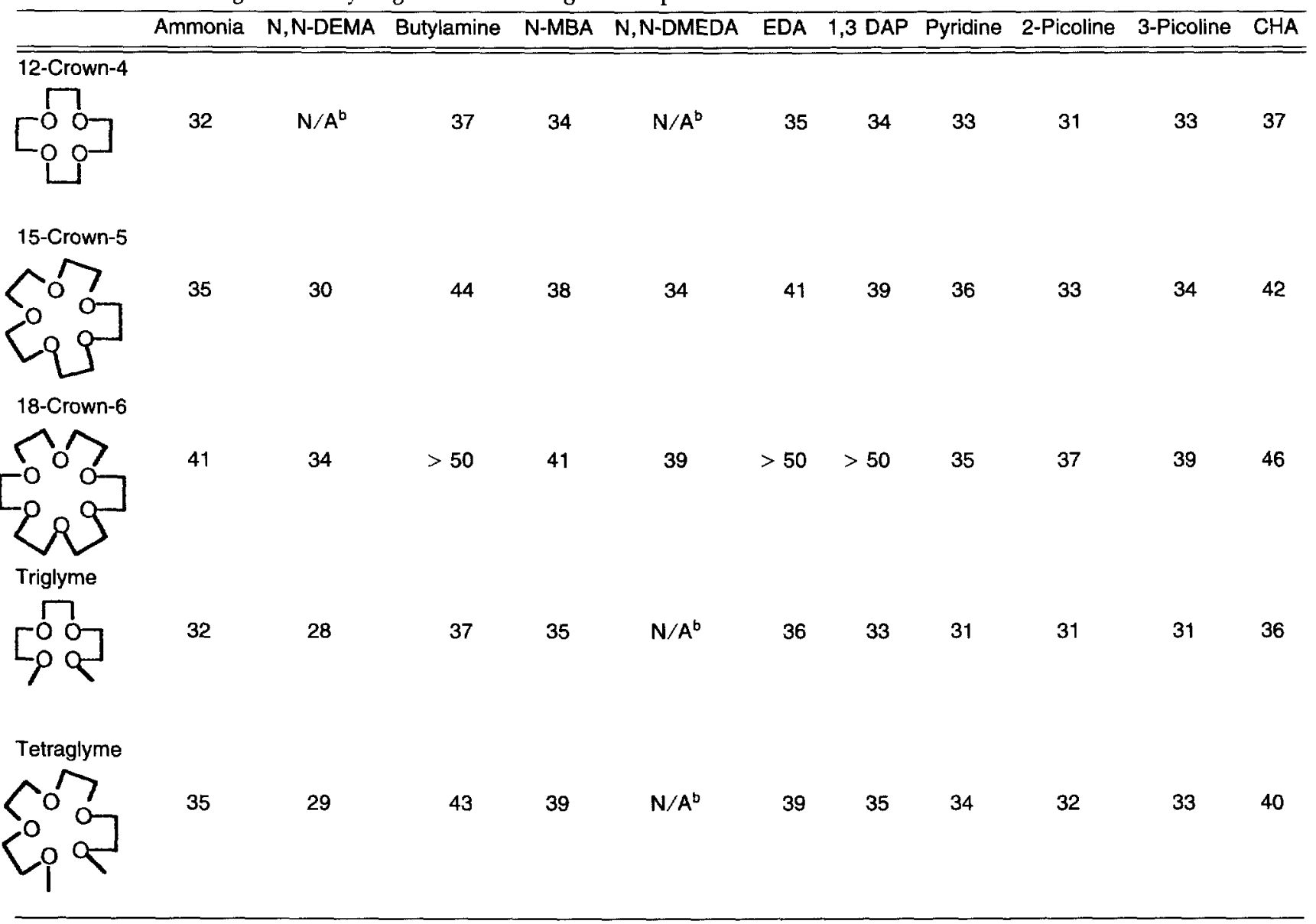

\footnotetext{
a All values in kilocalories per mole. The standard deviation is estimated as $\pm 2 \mathrm{kcal} / \mathrm{mol}$.

${ }^{b} \mathrm{~N} / \mathrm{A}=$ dimer does not form.
} 
two effects are counteractive, which results in association energies for the glyme complexes that are similar to those noted for the crown ether complexes.

With respect to the association energies of the polyether-amine complexes, there is a definite interplay between the intrinsic gas-phase basicity of each component in the complex and the number of possible hydrogen-bonding interactions of each component. As the number of possible hydrogen-bonding interactions increases, the potential for a greater association energy increases. For example, $\mathrm{NH}_{3}$ has three hydrogens that may serve as donors in hydrogen-bonding interactions, whereas pyridine has only one. From this simple view, ammonia has a more favorable structure to generate strongly bound complexes. However, the difference in gas-phase basicities between the two components in a complex also has a great impact on the stability of the complex. For complexes in which the difference in intrinsic basicities is large, then one component will bind the proton more strongly, which therefore reduces the critical energy for dissociation. For instance, the gas-phase basicity of pyridine is $213.1 \mathrm{kcal} / \mathrm{mol}$, the gas-phase basicity is only $195.6 \mathrm{kcal} / \mathrm{mol}$ for ammonia, and the gas-phase basicity of 15-crown-5 is $212.5 \mathrm{kcal} / \mathrm{mol}$ [55]. The intrinsic basicities are most similar for pyridine and 15-crown-5, which indicates that the [15-crown-5 $+\mathrm{H}^{+}+$pyridine] complex is predicted to be thermochemically most stable, assuming formation of complexes with only one strong hydrogen bond. The critical energy for the [15-crown-5 $+\mathrm{H}^{+}+$ $\mathrm{NH}_{3}$ ] complex is $35 \mathrm{kcal} / \mathrm{mol}$, whereas the critical energy for the [15-crown-5 $+\mathrm{H}^{+}+$pyridine] complex is $36 \mathrm{kcal} / \mathrm{mol}$, despite the fact that the latter complex has only one active hydrogen bond. The [15-crown-5 + $\mathrm{H}^{+}+\mathrm{NH}_{3}$ ] complex potentially has three or four hydrogen bonds, which creates a large association energy and consequently a high critical energy for dissociation, but the large difference in gas-phase basicities likely moderates the net effect. This latter factor is greatly reduced when the amine guest is changed from $\mathrm{NH}_{3}$ to butylamine, which still permits three hydrogen-bonding interactions but has a larger intrinsic basicity overall $(210.6 \mathrm{kcal} / \mathrm{mol})$. The gas-phase basicity of butylamine is substantially closer to that of 15crown-5 relative to the difference in basicities between 15-crown-5 and ammonia. The critical energy for the [15-crown-5 $+\mathrm{H}^{+}+$butylamine] complex is estimated as $44 \mathrm{kcal} / \mathrm{mol}$, which shows an increase of $9 \mathrm{kcal} / \mathrm{mol}$ relative to the $\left[15-\right.$ crown $\left.-5+\mathrm{H}^{+}+\mathrm{NH}_{3}\right]$ complex. In summary, correlation of the gas-phase basicities and the number of possible hydrogen-bonding interactions enables an understanding of the structural factors that influence the stabilities of loosely bound complexes.

\section{Conclusions}

Estimation of critical energies by a rapid energyresolved threshold CAD method appears feasible in a quadrupole ion trap. A plot of threshold activation voltage versus known critical energy values shows a linear correlation, and thus a calibration curve can be constructed to determine critical energies for new ions. Critical energies can be estimated with accuracies of $\pm 6 \mathrm{kcal} / \mathrm{mol}$ for most ions, with a standard deviation of $\pm 2 \mathrm{kcal} / \mathrm{mol}$. This technique is relatively fast to perform, reproducible, and not affected by many changes in experimental parameters. However, separate calibration curves must be constructed for radical ions that dissociate by covalent bond cleavages versus protonated complexes that dissociate by cleavage of hydrogen bonds, and there exist some unanswered questions about why the calibration curves differ. The main limitation of the method is that the construction and extension of the calibration curve requires accurate critical energy values obtained from other methods; that is, for systems that have similar sizes and bonding interactions to the ones of special interest. Thus, one must know some information about the nature of the bonding interactions in the ions under investigation prior to application of the method and have access to established critical energy values for calibrant systems.

\section{References}

1. McLuckey, S. A.; Glish, G. L.; Cooks, R. G.; Int. J. Mass Spectrom. Ion Phys. 1981, 39, 219-230.

2. Glish, G. L.; McLuckey, S. A.; Ridley, T. Y.; Cooks, R. G. Int. J. Mass Spectrom. Ion Phys. 1982, 41, 157-177.

3. Brodbelt, J. S.; Kenttamaa, H. I.; Cooks, R. G. Org. Mass Spectrom. OMS 1988, 23, 6-9.

4. Graul, S. T.; Squires, R. R. I. Am. Chem. Soc. 1990, 112, $2517-2529$.

5. Su, C-X.; Hales, D. A.; Armentrout, P. B. Chem. Phys. Lett. 1993, 201, 199-204.

6. Dalleska, N. F.; Honma, K.; Armentrout, P. B. J. Am. Chem. Soc. 1993, 115, 12125-12131.

7. Armentrout, P. B. Adams, N.; Babcock, L., Eds.; In Advances in Gas Phase Ion Chemistry; JAI Press: Greenwich, CT, 1992; Vol. $1 ; \mathrm{p} 83$.

8. Anderson, S. G.; Blades, A. T.; Klassen, J.; Kebarle, P. Int. J. Mass Spectrom. Ion Processes 1995, 141, 217-228.

9. Hop, C. E. C. A.; McMahon, T. B.; Willet, G. D. Int. J. Mass Spectrom. Ion Processes 1990, 101, 191-208.

10. Loh, S. K.; Hales, D. A.; Lian, L., Armentrout, P. B. I. Chem. Phys. 1989, 90, 5466.

11. Sunderlin, L. S.; Wang, D., Squires, R. R. J. Am. Chem. Soc. 1993, 115, 12060

12. Weddie, G. H.; Dunbar, R. C.; Song, K.; Morton, T. H. J. Am. Chem. Soc. 1995, 117, 2573-2580.

13. Dunbar, R. C. J. Phys. Chem. 1994, 98, 8705-8712.

14. Lin, C-Y.; Dunbar, R. C. J. Phys. Chem. 1995, 99, 1754-1759.

15. Simek, P.; Jegorov, A,; Dusbabek, F. I. Chromatogr. A 1994, $679,195-200$.

16. Ghoos, Y.; Claus, D.; Geypens, B.; Hiele, M.; Maes, B.; Rutgeerts, P. J. Chromatogr. A 1994, 665, 333-345.

17. Chichila, T. M. P.; Erney, D. R. I. Assoc. Off. Anal. Chem. $1994,77,1574-1580$.

18. Lehotay, S. J.; Tbrahim, M. A. I. Assoc. Off. Anal. Chem. 1995, $78,445-452$.

19. Lehotay, S. J.; Eller, K. I. J. Assoc. Off. Anal. Chem. 1995, 78 , 821-830. 
20. Chien, B. M.; Lubman, D. M. Anal. Chem. 1994, 66, 1630-1636.

21. Cox, K. A.; Williams, J. D.; Cooks, R. G.; Kaiser, R. E. Biol. Mass Spectrom. 1992, 21, 226-241.

22. Kamar, A.; Young, A. B.; March, R. E. Can. J. Chem. 1986, 64, 2368-2370.

23. Armitage, M. A.; Higgins, M. J.; Lewars, E. G.; March, R. E. J. Am. Chem. Soc. 1980, 102, 5064-5068.

24. Brodbelt, J. S.; Cooks, R. G. Talanta 1989, 36, 255-260.

25. Isbell, I. I.; Brodbelt, J. S. Proceedings of the 43rd ASMS Conference on Mass Spectrometry and Allied Topics; Atlanta, GA, May 1995; p 54.

26. Bonner, R. F.; Lawson, G.; Todd, J. F. J. Int. J. Mass Spectrom. Ion Phys. 1972 / 73, 10, 197-203.

27. Bonner, R. F.; March, R. E; Durup, J. Int. I. Mass Spectrom. Ion Phys. 1976, 22, 17-34.

28. March, R. E.; McMahon, A. W.; Londry, F. A.; Alfred, R. L.; Todd, J. F. J.; Vedel, F. Int. J. Mass Spectrom. Ion Processes 1989, 95, 119-156.

29. Basic, C.; Eyler, J. R.; Yost, R. A. J. Am. Soc. Mass Spectrom. 1992, 3, 716-726.

30. Nourse, B.; Kenttamaa, H. I. I. Phys. Chem. 1990, 94, 5809-5812.

31. McLuckey, S. A.; Glish, G. L.; Asano, K. G.; Bartmess, J. E. Int. I. Mass Spectrom. Ion Processes 1991, 109, 171-186.

32. Dunbar, R. C. Int. J. Mass Spectrom. Ion Processes 1983, 54, 109-118.

33. Hart, K.; McCluckey, S. A. J. Am. Soc. Mass Spectrom. 1994, $5,250-259$.

34. Liou, C.-C.; Wu, H.-F.; Brodbelt, J. S. I. Am. Soc. Mass Spectrom. 1994, 5, 260-273.

35. March, R. E.; Hughes, R. J.; Todd, J. F. J. Quadrupole Storage Mass Spectrometry; Wiley: New York, 1989.

36. Norwood, A. A.; Flesch, J. D.; Ng, C. Y. J. Am. Chem. Soc. 1990, 112, 7502-7508.
37. Schultz, R. H.; Crellin, K. C.; Armentrout, P. B. I. Am. Chem. Soc. 1991, 113, 8590-8601.

38. Faulk, J. D.; Dunbar, R. C. I. Am. Chem. Soc. 1992, 114, 8596-8600.

39. de Ridder, J. J.; Dijkstra, G. Recl. Trav. Chim. 1967, 86, 737-745.

40. Nicholson, A. J. C. In Recent Developments in Mass Spectrometry; Ogata, K.; Hayakawa, T., Eds. University Park Press: Baltimore, MD, 1970; $p 745$.

41. Chen, J. H.; Hayes, J. D.; Dunbar, R. C. J. Phys. Chem. 1984, $88,4759-4764$.

42. McLoughlin, R. G.; Morrison, J. D; Traeger, J. C. Org. Mass Spectrom. 1979, 14, 104-108.

43. Bombach, R.; Dannacher, I.; Stadelmann, J-P. J. Am. Chem. Soc. 1983, 105, 4205-4211.

44. Dunbar, R. C. I. Phys. Chem. 1990, 94, 3283-3286.

45. Hiraoka, K.; Takimoto, H.; Yamabe, S. J. Phys. Chem. 1986, 90, 5910-5914.

46. Bomse, D. S.; Beauchamp, J. L. I. Phys. Chem. 1981, 85, $488-492$.

47. Meot-Ner, M. J. Am. Chem. Soc. 1983, 105, 4912-4915.

48. Meot-Ner, M. J. Am. Chem. Soc. 1979, 101, 2396-2403.

49. Charles, J. M.; McLuckey, S. A.; Glish, G. L. J. Am. Soc. Mass Spectrom. 1994, 5, 1031-1041.

50. Chang, S-K.; Hamilton, A. D. J. Am. Chem. Soc. 1988, 110, 1318-1319.

51. Chang, S-K.; Engen, D. V; Fan, E.; Hamilton, A. D. I. Am. Chem. Soc. 1991, 113, 7640-7645.

52. Hamilton, A. D.; Engen, D. V. J. Am. Chem. Soc. 1987, 109, 5035-5036.

53. Feibush, B.; Figueroa, A.; Charles, R.; Oran, K. D.; Feibush, P.; Kagar, B. L. J. Am. Chem. Soc. 1986, 108, 3310-3318.

54. Meot-Ner, M.; Sieck, L.; Liebman, J. F.; Scheiner, S. J. Phys. Chem., 1996, 100, 6445-6450.

55. Lias, S. G.; Liebman, J. F.; Levin, R. D. J. Phys. Chem. Ref. Data 1984, 13, 695. 